Running Head : Advancing Measurement of Psychological Need States

\title{
Advancing the Conceptualization and Measurement of Psychological Need States: A 3 x 3 Model Based on Self-Determination Theory
}

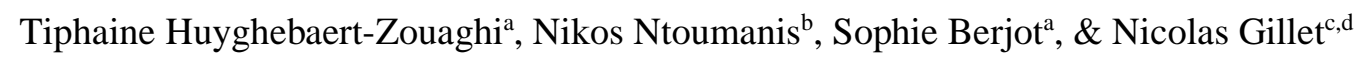

${ }^{a}$ Université de Reims Champagne Ardenne, France (E.A. 6291 Laboratoire C2S)

${ }^{\mathrm{b}}$ Curtin University, Australia (School of Psychology; Physical Activity and Well-Being Research Group)

${ }^{\mathrm{c}}$ Université de Tours, France (E.E. 1901 QualiPsy)

${ }^{\mathrm{d}}$ Institut Universitaire de France (IUF)

\section{Corresponding author :}

Tiphaine Huyghebaert-Zouaghi

Université de Reims

Laboratoire C2S (E.A. 6291)

UFR Lettres et Sciences Humaines, Département de Psychologie

57 rue Pierre Taittinger, 51100 Reims, France

tiphaine.huyghebaert@univ-reims.fr

This is the postprint version of the following manuscript (accepted for publication) :

Huyghebaert-Zouaghi, T., Ntoumanis, N., Berjot, S., \& Gillet, N. (2020). Advancing the conceptualization and measurement of psychological need states: A 3 x 3 Model Based on SelfDetermination Theory. Journal of Career Assessment. Advance online publication. https://doi.org/10.1177/1069072720978792

(C) 2020. This paper may not exactly replicate the authoritative document to be published. 


\begin{abstract}
Based on Self-Determination Theory (SDT), this research aimed to investigate whether employees' psychological need states could be expanded from two (need satisfaction and frustration) to three (need satisfaction, frustration, and unfulfillment). Relying on exploratory structural equation modeling (ESEM) and bifactor-ESEM, this research also offered to test the construct validity of the Psychological Need States at Work-Scale (PNSW-S) and to explore its criterion-related validity. Results from two studies and three distinct samples of employees (French and English speaking) provided support for the unfulfillment of the needs for autonomy, competence, and relatedness to be modeled as a distinct need state when tested alongside the satisfaction and frustration of those three needs. Moreover, results indicated that the different need states appeared to stem from distinct experiences (perceived supervisors' supportive and thwarting behaviors) and that these need states in turn had well-differentiated effects in terms of employee functioning (job satisfaction, job boredom, and work-related rumination). Our research therefore deepens our understanding of the nature of psychological need states in the workplace and offers a multidimensional instrument allowing to simultaneously assess not only need satisfaction and frustration, but also need unfulfillment. It also indicates that SDT's explanatory framework may be expanded from two to three need processes to explain the effect of the socio-contextual environment on individual functioning.

Keywords: Interpersonal behaviors; need satisfaction; need frustration; need unfulfillment;
\end{abstract} Psychological Need States at Work-Scale; well-being; ill-being. 
Research in the field of Self-Determination Theory (SDT; Deci \& Ryan, 2000; Ryan \& Deci, 2017) has consistently demonstrated the importance of the basic psychological needs for autonomy (need to feel volitional and responsible for one's actions), competence (need to feel efficient when interacting with one's social environment and to have opportunities to express one's abilities), and relatedness (need to feel secure in one's relationships and to be able to rely on others) in promoting individuals' well-being. Scholars within SDT have demonstrated that there is both a beneficial and a detrimental aspect to these needs, with need satisfaction reflecting the positive experiential state of feeling that one's psychological needs are fulfilled, and need frustration referring to the negative experience where one feels that their psychological needs are actively undermined (Bartholomew et al., 2011a). Research within various contexts, including the work domain, has corroborated the existence of these distinct need states and shown their differentiated effects, with need satisfaction leading to adaptive functioning and need frustration yielding maladaptive outcomes (e.g., Trépanier et al., 2015).

Yet, recent research has suggested that need satisfaction and frustration do not suffice to explain individuals' functioning, and that a third psychological need state, namely need unfulfillment (i.e., the experiential state of lack of need fulfillment; also labeled need dissatisfaction by some scholars), could help gain a deeper understanding of the motivational mechanisms leading to individuals' well- and illbeing (e.g., Bhavsar et al., 2020; Cheon et al., 2019; Costa et al., 2015). Yet, none of these studies was able to provide full validity evidence for the existence of need unfulfillment as a distinctive need state. Building upon these past studies, our first goal was to provide evidence to support a 3 x 3 conceptual model of the distinct experiential states of satisfaction, frustration, and unfulfillment, pertaining to each of the three needs for autonomy, competence, and relatedness (see Figure 1), in the work context.

The second objective of the present research was to operationalize this theoretical proposal by adapting the Psychological Need States in Sport-Scale (PNSS-S; Bhavsar et al., 2020), which taps on all three states, to the work context and to examine the construct validity of our Psychological Need States at Work-Scale (PNSW-S). Moreover, based on recent psychometric investigations into the multidimensional structure of need states ratings, including in the work context (e.g., Gillet et al., 2020; Huyghebaert-Zouaghi et al., 2020a), the third goal of our research was to further explore the multidimensionality of ratings on the PNSW-S. The fourth and final goal of the present research was 
to consider these multidimensional need states simultaneously, in order to gain a better understanding of their respective relations with conceptually proposed socio-contextual antecedents (supportive and thwarting supervisory behaviors) and consequences (job satisfaction, work-related rumination, and job boredom).

\section{Literature Review}

Recent research has provided some support for the existence of need unfulfillment. For instance, Costa et al. (2015) demonstrated that need unfulfillment was not equivalent to need frustration. Indeed, perceiving no meaningful connection with one's peers (i.e., relatedness unfulfillment) is the not the same psychological experience as feeling rejected or despised by others (i.e., relatedness frustration). However, Costa et al. (2015) did not provide full evidence for the existence of need unfulfillment by failing to assert its criterion-related validity. Cheon et al. (2019) were able to show autonomy unfulfillment to be distinct from autonomy satisfaction and frustration, as items measuring these concepts loaded on three separate factors with few cross-loadings. Yet, this study did not consider the experience of unfulfillment across all three needs.

Bhavsar et al. (2020) tried to address the limitations of prior studies by offering a tripartite conceptualization of psychological need states (need satisfaction, frustration, and unfulfillment). These authors proposed the term "need unfulfillment" as an alternative to the predominantly used "need dissatisfaction" label which, in prior research, was confusingly used to refer to lack of need fulfillment (e.g., Cheon et al., 2019) but also to describe the experience of need frustration (e.g., Neubauer \& Voss, 2018; Wang et al., 2019). Bhavsar et al. (2020) defined need unfulfillment as the "negative experiential state of a lack of need fulfillment" (p. 3), in which one perceives that their needs are set aside or neglected and feels that "something is not as good as it should be" (Bartholomew et al., 2011a, p. 78). Despite their rigorous conceptual and methodological approach, the authors found no evidence to demonstrate that need unfulfillment could be modeled as a distinct need state when tested alongside need satisfaction and frustration. Yet, they were able to show support for a distinct need unfulfillment factor when modelled alongside either of the other two need states.

In line with prior research's theoretical advancements, we suggest that employees, just like athletes (Bhavsar et al., 2020), students (Cheon et al., 2019), and individuals in a romantic relationship (Costa 
et al., 2015) may experience need satisfaction, frustration, and unfulfillment of their psychological needs for autonomy, competence, and relatedness. Specifically, based on Bhavsar et al.'s (2020) work and prior research on psychological needs in the work context (Bartholomew et al., 2014; van den Broeck et al., 2016), we propose that employees experience need satisfaction when they feel a sense of ownership of their actions at work (autonomy satisfaction), when they experience mastery and optimal challenge in their work environment (competence satisfaction), and when they feel mutual care and appreciation with other people at work (relatedness satisfaction). Conversely, employees experience need frustration when they feel coerced and oppressed in their work-related actions (autonomy frustration), when they are made to feel inadequate in their job (competence frustration), and when they feel despised, rejected, or ostracized by others at work (relatedness frustration). Finally, we propose that employees experience need unfulfillment when they are uncertain as to whether they can make decisions at work or experience ambiguity about the rationale underlying their work actions (autonomy unfulfillment), when they feel that they are not performing or improving like they would like to (competence unfulfillment), and when they feel that they do not have much in common with their peers, a sense of not fitting in (relatedness unfulfillment).

\section{Existing Measures of Work-Related Need States}

Importantly, the above-mentioned investigations of need unfulfillment were conducted in the educational (e.g., Cheon et al., 2019), sport (e.g., Bhavsar et al., 2020), or interpersonal relationships (e.g., Costa et al. 2015) contexts. No research has yet considered the experiential state of need unfulfillment in the work domain and, hence, no work-specific measure of the three need states has been developed. In the work setting, the state of need satisfaction has received by far the most research attention. Several instruments have been developed to measure this need state, yet these measurement tools have some limitations. The foundational Basic Need Satisfaction at Work scale (BNSW; Deci et al., 2001) was not rigorously validated and contains items referring to socio-contextual antecedents (e.g., "People at work tell me I am good at what I do") or consequences (e.g., "I enjoy the challenge my work provides") of need satisfaction. Other researchers (e.g., Huyghebaert et al., 2018b) have adapted scales which were originally designed to measure need satisfaction in other domains (e.g., sport; Gillet et al., 2008) but they did not validate these scales in the work context. The widely used 
Work-Related Basic Need Satisfaction scale (WRBNS; Van den Broeck et al., 2010) did go through a rigorous validation process and showed support for a tripartite factor structure (autonomy, competence, relatedness) for need satisfaction ratings. Yet, the WRBNS contains items that, via reverse coding, tap into need frustration (e.g., "In my job, I feel forced to do things I do not want to do") and need unfulfillment (e.g., "I doubt whether I am able to execute my job properly"). Brien et al. (2012) addressed some of these limitations by validating their Basic Psychological Needs at Work Scale, yet this scale only measures one need state (i.e., need satisfaction).

Need frustration has been less explored in the work context, hence fewer instruments have been developed to assess this need state. Employees' need frustration has been assessed through scales which were originally designed to measure this need state in other life domains but which were not validated in the work context (e.g., Bartholomew et al., 2014; Bidee et al., 2016; Schultz et al., 2015). Gillet and colleagues (2012b) did adapt the Psychological Need Thwarting Scale (PNTS;

Bartholomew et al., 2011a) from the sport to the work context and validated it but only in the French language; also, this scale does not tap need satisfaction nor need unfulfillment. Need frustration has also been measured through the use of a partly reverse-coded WRBNS (Van der Elst et al., 2012), but evidence shows that low need satisfaction does not equal need frustration (Bartholomew et al., 2011a).

This lack of consensus in the measures used to assess need satisfaction and frustration has important implications as these instruments may vary in terms of their predictive validity (van den Broeck et al., 2016), thus questioning the generalizability of the findings in this field of research. To date, no scale exists to simultaneously measure work-related need satisfaction and frustration. This emphasizes the need for a more integrative, multidimensional measure of workers' psychological need satisfaction and frustration, as well as unfulfillment, which could be addressed by our PNSW-S.

\section{A Multidimensional Measurement Perspective on Psychological Need States}

When considering employees' ratings of their experiences of satisfaction, frustration, and unfulfillment of their needs for autonomy, competence and relatedness, a key question that has to be addressed is related to the inherent multidimensionality of these ratings. Indeed, although these three constructs may seem to reflect different points on a continuum ranging from need satisfaction to need frustration, with need unfulfillment somewhere in the middle of the continuum, it is fundamental to 
note that these constructs are conceptualized as distinct need states (Bartholomew et al., 2011a; Costa et al., 2015). For instance, low levels of autonomy satisfaction at work do not necessarily imply high levels of autonomy frustration or of autonomy unfulfillment. In sum, over time, these three need states can co-occur within a given context (Costa et al., 2015). However, despite their distinct nature, need satisfaction, frustration, and unfulfillment (Costa et al., 2015) tend to be moderately to highly correlated. Moreover, the needs for autonomy, competence, and relatedness are also known to be highly inter-correlated. (e.g., Jang et al., 2009; Vansteenkiste et al., 2006). These results thus call into question the relative independence of each of the three needs and their experiential states (Figure 1) and raise some multidimensionality issues associated with need states ratings.

Interestingly, recent research has shown that bifactor modeling and exploratory structural equation modeling (ESEM) allow to address two multidimensionality issues that may be present in multidimensional instruments designed to measure employees' psychological need states (e.g., Gillet et al., 2020; Huyghebaert-Zouaghi et al., 2020a; Sánchez-Oliva et al., 2017). These multidimensionality issues are ignored in more traditional CFA approaches (including Structural Equation Modeling). The first multidimensionality issue, addressed by bifactor modeling, is the disaggregation of global $(\mathrm{G})$ and specific (S) components. Recent research has shown that psychological need states ratings could in fact be disaggregated into two independent (i.e., uncorrelated) components (e.g., Gillet et al., 2020; Sánchez-Oliva et al., 2017). The first of those components (G-factor) reflects global levels of one's need state experience across all needs and experiential states. The second component (S-factor) reflects the more specific levels of need satisfaction, frustration, and unfulfillment of each need, left unexplained by the global level of need states. The second multidimensionality issue, addressed by ESEM, is that specific item ratings may sometimes reflect more than one latent construct (i.e., cross-loadings; Morin et al., 2016a, 2017). Such cross-loadings could appear because of the naturally imperfect nature of the ratings, but also because the underlying factors (e.g., need satisfaction, frustration, and unfulfillment) are conceptually interrelated (Bhavsar et al., 2020; Costa et al., 2015). The bifactor-ESEM approach thus provides a means to simultaneously account for both forms of multidimensionality. Its adequacy to represent ratings on the PNSW-S will be considered in this research. 


\section{Antecedents and Consequences of Psychological Need States}

Research based on SDT has consistently shown the key role played by need-supportive and thwarting supervisory behaviors in the prediction of employees' psychological need states (e.g., Gillet et al., 2012a; Slemp et al., 2018). Indeed, the interpersonal climate created by supervisors is proposed to be crucial for employees' psychological experiences at work (Olafsen \& Deci, 2020). Therefore, we chose to explore supervisors' supportive and thwarting behaviors toward their subordinates' needs for autonomy, competence, and relatedness in relation to employees' psychological need states. In doing so, we aimed to address several gaps in the literature. First, to date, only one study has looked into the predictors of all three need states (Cheon et al., 2019) and has considered only autonomy support as an antecedent of these experiential states. This is common in the SDT research, particularly in the work setting, where autonomy-supportive behaviors, and to a lesser extent autonomy-thwarting (controlling) behaviors, have received most of the attention (e.g., Gillet et al., 2012a; Moreau \& Mageau, 2012; Schultz et al., 2015). However, recent research in other domains has shown the importance of taking into consideration how some individuals (e.g., coaches, peers) may support all three psychological needs of those they interact with (Bhavsar et al., 2019; Rocchi et al., 2017a, 2017b; Tóth-Kiraly et al., 2020). As such, the present research offers to simultaneously assess the other types of supportive (competence support and relatedness support) and thwarting (competence thwarting and relatedness thwarting) behaviors from supervisors, together with autonomy support and thwarting, as antecedents of need states.

Second, no study has to date looked into the negative antecedents of all three need states. Yet, based on SDT findings, one would expect employees' need frustration and unfulfillment to stem from negative forms of interpersonal behaviors, such as need thwarting behaviors (e.g., Bartholomew et al., 2011b; Gillet et al., 2012a). Indeed, past research has demonstrated that negative socio-contextual factors (e.g., supervisory thwarting behaviors), because they are more destructive in nature, are more likely to yield adverse psychological experiences such as need frustration or unfulfillment (Bartholomew et al., 2011b; Trépanier et al., 2015). Contrastingly, positive socio-contextual factors (e.g., supportive behaviors from supervisors), because they nurture individuals' inner resources, are more likely to promote optimal psychological experiences such as need satisfaction. Therefore, we 
hypothesized that need satisfaction would be best predicted by supervisory supportive behaviors, while need frustration and, though to a lesser extent, need unfulfillment would be best predicted by need thwarting behaviors from supervisors.

In terms of consequences of the need states, we examined job satisfaction, work-related rumination, and job boredom, as these variables have been shown to be relevant outcomes of need states (Gillet et al., 2012a; van Hooff \& van Hooft, 2017; Weigelt et al., 2019), and to be associated with important organizational consequences such as turnover intentions, sickness absence, performance, and organizational commitment (Lu et al., 2019; Lyubomirsky \& Tkach, 2003; Schaufeli \& Salanova, 2014). We included these indices of well- (job satisfaction) and ill-being (work-related rumination and job boredom) to cover both positive and negative aspects of workers' functioning, as both facets are necessary to allow for a complete and balanced understanding of psychological health (Keyes, 2005).

In line with prior findings, we hypothesized that job satisfaction would be best predicted by need satisfaction (Gillet et al., 2012a; Huyghebaert et al., 2018b). Indeed, when the work environment allows individuals to feel independent, efficient, and appreciated, they are provided with those psychological resources that promote their well-being (Deci \& Ryan, 2008). Contrastingly, need frustration and unfulfillment have been argued to predict indicators of ill-being that differ in nature: Need frustration is proposed to be a better predictor of intensely adverse maladaptive outcomes (e.g., burnout, work-family conflict, psychological distress; Huyghebaert et al., 2018a; Trépanier et al., 2015), and need unfulfillment to better predict passive forms of maladaptive functioning (e.g., amotivation, boredom, disengagement; Cheon et al., 2019). Indeed, feeling that one's psychological needs are neglected in the workplace may not be as harmful as feeling that these needs are undermined. Hence, need unfulfillment may yield less deleterious consequences in employees than need frustration.

Based on the above-mentioned arguments, we hypothesized that need frustration would best predict work-related rumination (i.e., the experience of recurring and invasive thoughts about work-related matters in the absence of job demands necessitating these thoughts; Martin \& Tesser, 1996). Indeed, the psychological experience of feeling coerced, useless, and excluded may spill over to employees' free time in the form of pervasive thoughts (Bakker \& Demerouti, 2013). In contrast, job boredom also 
constitutes a negative outcome but not as adverse as work-related rumination, just like need unfulfillment is less actively negative than need frustration (Bartholomew et al., 2011a, 2011b). Moreover, job boredom refers to "an unpleasant state of relatively low arousal and dissatisfaction" (Mikulas \& Vodanovich, 1993, p. 3) stemming from an inadequately stimulating work situation (Schaufeli \& Salanova, 2014) and may thus logically arise from need unfulfillment which reflects a "feeling that something is not as good as it should be" (Bartholomew et al., 2011a, p. 78). We thus hypothesized that job boredom would be best predicted by need unfulfillment.

\section{The Present Research}

Two studies were conducted to pursue our research's objectives. In Study 1, we examined the construct validity of the PNSW-S in English and in French. Indeed, given that the needs for autonomy, competence, and relatedness are proposed to be crucial to human thriving across diverse cultural backgrounds (for cross-cultural meta-analytic evidence see Slemp et al. 2018; Yu et al. 2018), testing whether the PNSW-S is equally applicable across different languages and countries could be valuable to researchers and practitioners. In Study 2, we further tested the construct validity of this measure in a new sample and attempted to provide initial evidence of its criterion-related validity.

\section{Study 1}

Study 1 was designed to provide an initial investigation of the factor structure of the PNSW-S in English- and French-speaking employees. We contrasted alternative representations of employees' responses to the PNSW-S in order to rigorously test the multidimensionality of this measure.

\section{Method}

\section{Procedure}

English-speaking sample. Participants were recruited through the Prolific Academic online platform, a crowdsourcing service based in the United Kingdom. This platform is explicitly targeted for academic research and was recognized for providing quality data (Palan \& Shitter, 2018; Peer et al., 2017). We used pre-screening criteria to recruit only participants who (1) spoke English as a first language, and who were currently (2) employed, (3) not self-employed or working without pay, (4) working full-time or part-time, and (5) working and living in the United Kingdom, the United States of America, or Canada. Before taking part in the survey, participants were explained the general purpose 
of the study, that they were free to withdraw from the survey at any time, were assured that their responses would be kept anonymous and that the data would solely be used for research purposes. They were also informed about the compensation for this five-minute study (£0.55 per participant). After receiving all this information, respondents were invited to provide written informed consent.

To make sure that participants' responses were trustworthy, two attention checks were included (e.g., "It is important that you pay attention to our survey, please tick strongly disagree"), which split the questionnaire into three equal parts. Additionally, at the very end of the questionnaire, participants were asked to indicate "for scientific reasons" whether they were really currently working in an organization, while being assured that their response would not affect their compensation. A total of 24 attention checks were failed and linked to 21 participants who were thus excluded from the sample.

French-speaking sample. Participants were recruited by three Masters' students following the same criteria as with the English-speaking sample, except that respondents had to be living and working in France. The procedures used were the same as those for the English-speaking sample.

\section{Participants}

English-speaking sample. A total of 345 participants $\left(M_{\mathrm{age}}=38.08 ; S D=10.58\right)$ completed the survey. Most were women (57.7\%), $41.7 \%$ were men, $0.3 \%$ identified as non-binary, and $0.3 \%$ preferred not to answer. Participants lived and worked either in the United Kingdom (67.8\%), the United States of America (27.5\%), or Canada (4.6\%). Most participants had a permanent contract (92.2\%), 6.1\% had a fixed-term contract, and 1.7\% had other types of contract (e.g., zero-hour contract). Participants had been working in their current job position for 5.64 years on average $(S D=$ 5.06). Most of them worked full-time $(76.8 \%), 35.6$ hours a week $(S D=9.06)$ in average. They mostly worked in the private sector (67\%); specifically in non-market services (41.4\%), market services (37.7\%), industry (12.2\%), construction (5.5\%), and agriculture (0.9\%), while $2.3 \%$ did not specify.

French-speaking sample. A total of 440 participants who all lived and worked in France $\left(M_{\text {age }}=\right.$ $36.29 ; S D=12.68)$ completed the survey. Most were women $(68.6 \%), 31 \%$ were men, $0.2 \%$ identified as non-binary, and $0.2 \%$ preferred not to answer. Most participants had a permanent contract (73\%), while $24.8 \%$ had a fixed-term contract, and $2.3 \%$ had other types of contract (e.g., temporary work). Participants had been working in their current job position for 6.83 years on average $(S D=8.09)$. Most 
worked full-time $(82.7 \%)$ and, on average, 38.95 hours a week $(S D=14.08)$. Participants mostly worked in the private sector (63.6\%); specifically in non-market services (45.9\%), market services (25.9\%), industry (11.1\%), construction (2.3\%), agriculture (1.1\%), and 3.6\% did not specify.

\section{Measures}

Psychological need states were measured with the 46-item PNSW-S. In the English version, we adapted the items developed by Bhavsar et al. (2020) to the work context by replacing expressions such as "my training" by "my work", and by changing the stem "In my sport, I..." to "In my job, I...". This modified version was translated from English to French using a back-translation method (e.g., Beaton et al., 2000). Workers were asked to consider their general experience in their current job to indicate their level of agreement with each of the 46 statements using a seven-point response scale. Sixteen items measured need satisfaction: Five items for autonomy (e.g., “...feel free to make choices with regards to the way I work"), five items for competence (e.g., "...am able to overcome challenges”), and six items for relatedness (e.g., “...feel supported”). Fifteen items assessed need frustration: five items for autonomy (e.g., “... feel a lot of unwanted pressure”), four items for competence (e.g., “...... feel like a failure”), and six items for relatedness (e.g., “...feel isolated”). Fifteen items measured need unfulfillment: five items for autonomy (e.g., "...find many of the activities set for me are boring”), five items for competence (e.g., “...feel like I have achieved less than I would have liked to"), and five items for relatedness (e.g., “...feel I don't quite fit in with others").

\section{Analyses}

All analyses utilized the Maximum Likelihood Robust (MLR) estimator, available in the Mplus 8 statistical package (Muthén \& Muthén, 2018), which provides parameter estimates, standard errors, and goodness-of-fit indices that are robust to non-normal data distributions. No missing responses were present given the online questionnaire was set-up so that not to allow such responses.

In line with past studies (e.g., Bhavsar et al., 2020; Tóth-Király et al., 2018), a series of confirmatory factor analyses (CFA) and ESEM models were tested: (a) one-factor CFA (Model 1); (b) three-factor CFA (Model 2) and ESEM (Model 3) models (need satisfaction, frustration, and unfulfillment); (c) three-factor CFA (Model 4) and ESEM (Model 5) models (autonomy, competence, 
and relatedness); (d) nine-factor CFA (Model 6) and ESEM (Model 7) models (autonomy satisfaction, relatedness satisfaction, competence satisfaction, autonomy frustration, relatedness frustration, competence frustration, autonomy unfulfillment, relatedness unfulfillment, and competence unfulfillment); (e) bifactor CFA (Model 8) and ESEM (Model 9) models with three S-factors (need satisfaction, frustration, and unfulfillment) and one G-factor (global psychological needs); (f) bifactor CFA (Model 10) and ESEM (Model 11) models including three S-factors (autonomy, competence, and relatedness) and one G-factor (global psychological needs); (g) bifactor CFA (Model 12) and ESEM (Model 13) models with three S-factors (autonomy, competence, and relatedness) and three G-factors (need satisfaction, frustration, and unfulfillment); (h) bifactor CFA (Model 14) and ESEM (Model 15) models including nine S-factors (autonomy satisfaction, relatedness satisfaction, competence satisfaction, autonomy frustration, relatedness frustration, competence frustration, autonomy unfulfillment, relatedness unfulfillment, and competence unfulfillment) and one G-factor (global psychological needs); and (i) bifactor CFA (Model 16) and ESEM (Model 17) models with nine Sfactors (autonomy satisfaction, relatedness satisfaction, competence satisfaction, autonomy frustration, relatedness frustration, competence frustration, autonomy unfulfillment, relatedness unfulfillment, and competence unfulfillment) and three G-factors (need satisfaction, frustration, and unfulfillment).

In the CFA models, items were only allowed to define their a priori factors, factors were allowed to correlate, and no cross-loadings were estimated. In the ESEM models, the factors were defined as in the CFA models, and all cross-loadings were freely estimated but assigned a target value of zero using an oblique target rotation procedure (Browne, 2001). In bifactor CFA models, items were allowed to define one a priori S-factor as well as one G-factor, and most factors were specified as orthogonal, although G-factors were allowed to correlate with one another in models including more than one Gfactor. Bifactor ESEM models were specified as their bifactor CFA counterparts, although all crossloadings involving the S-factors were freely estimated but assigned a target value of zero using an orthogonal bifactor target rotation procedure (Reise, 2012).

Given the known oversensitivity of the chi-square test of exact fit $\left(\chi^{2}\right)$ to sample size and minor model misspecifications (e.g., Marsh et al., 2005), we relied on other goodness-of-fit indices to describe the fit of the alternative models (Hu \& Bentler, 1999): The comparative fit index (CFI), the 
Tucker-Lewis index (TLI), the standardized root mean squared residual (SRMR), and the root mean square error of approximation (RMSEA) and its $90 \%$ confidence interval. Values greater than .90 for the CFI and TLI indicate adequate model fit, although values greater than .95 are preferable. Values smaller than .08 or .06 for the RMSEA support acceptable and excellent model fit, respectively. As noted by Morin et al. (Morin et al., 2016a, 2017), fit indices are not sufficient to guide the selection of the optimal model. An examination of the parameter estimates is also required to select the best alternative. When contrasting a CFA or an ESEM solution with a bifactor alternative, the key elements supporting a bifactor representation are: (1) an improved level of fit to the data; (2) a well-defined (i.e., presenting moderate to strong significant target loadings) as opposed to a weakly defined (i.e., weak target loadings) G-factor; and (3) at least some reasonably well-defined S-factors. It should be noted that there is no formal guideline regarding the exact values beyond which one can interpret factors to be well-defined and S-factors to retain enough specificity. Instead, target loadings and model-based coefficients of composite reliability (omega coefficient; $\omega$ ) are typically interpreted in a more holistic manner. However, prior research on psychological need states within the bifactor ESEM framework (e.g., Gillet et al., 2020; Huyghebaert-Zouaghi et al., 2020a; Sánchez-Oliva et al., 2017; Tóth-Kiraly et al., 2018) seems to suggest that G-factors may be considered well-defined when they present target loadings approximating or exceeding .400 and a coefficient of composite reliability near or above .600. S-factors tend to be weaker in bifactor representations than in first-order models (CFA or ESEM) because bifactor models rely on two factors to explain the covariance present at the item level for each specific item (Morin et al., 2016b). Hence, slightly lower loadings and composite reliability values on S-factors are seen as acceptable and reflecting sufficient remaining specificity beyond what is covered by the G-factor. In terms of cross-loadings, values greater than .100 or .200 in ESEM that are reduced in bifactor ESEM is a source of evidence in favor of the bifactor over the ESEM solution (Morin et al., 2016a).

\section{Results}

\section{Estimated Measurement Models}

In both samples, only three solutions were able to achieve an acceptable level of fit to the data 
(Models 7, 15, and 17; see Tables S1 and S2 of the Supplementary File ${ }^{1}$ for further details on goodness-of-fit results from all models). The ESEM solution with nine factors (Model 7) showed an adequate fit to the data in both the English $\left(\chi^{2}(d f)=1177.430(657)\right.$, CFI $=.953$, TLI $=.927$, SRMR $=$ .016 , and RMSEA $=.048[.043 ; .052])$ and the French $\left(\chi^{2}(d f)=1114.724(657)\right.$, CFI $=.961$, TLI $=$ .939$, SRMR $=.017$, and RMSEA $=.040[.036 ; .044])$ versions of the PNSW-S. This solution resulted in a majority of well-defined factors and a minority of more weakly-defined factors (factor definition is further detailed in the Supplementary File). More specifically, for these weakly defined factors, there was a total of 12 items with low factor loadings $(<.400)$ and/or high cross-loadings $(>.350)$. These 12 problematic items were the same in both the English-speaking and the French-speaking samples. Interestingly, five of these 12 items were removed by Bhavsar et al. (2020) from the final version of the PNSS-S (which measured need satisfaction and frustration, but not unfulfillment).

Turning our attention to the bifactor representations (Models 15 and 17), the critical question when interpreting such solutions is whether the G-factor taps into a meaningful amount of covariance shared among all items, and whether sufficient specificity remains at the subscale level, unexplained by the G-factor, to result in the estimation of meaningful S-factors. The bifactor ESEM solution with one Gfactor and nine S-factors (Model 15) showed adequate fit to the data in both the English $\left(\chi^{2}(d f)=\right.$ $1283.728(620), \mathrm{CFI}=.941, \mathrm{TLI}=.901, \mathrm{SRMR}=.016$, and RMSEA $=.056[.051 ; .060])$ and the French $\left(\chi^{2}(d f)=1027.148(620), \mathrm{CFI}=.965, \mathrm{TLI}=.942, \mathrm{SRMR}=.016\right.$, and RMSEA $=.039[.034$ .043]) versions of the PNSW-S. This solution revealed a well-defined G-factor with negative factor loadings associated with the need satisfaction items, and positive factor loadings associated with the need frustration and unfulfillment items (factor definition is further examined in the Supplementary File). Similarly, with the exception of few items which mainly reflected the global psychological needs G-factor rather than their own a priori S-factors, the S-factors retained at least some degree of meaningful specificity over and above employees' global levels of psychological needs. The S-factors with the lowest levels of specificity (autonomy satisfaction, competence satisfaction, autonomy frustration, autonomy unfulfillment, and competence unfulfillment for the English-speaking sample;

\footnotetext{
${ }^{1}$ The supplementary file is available upon request from the first author.
} 
and competence satisfaction, autonomy unfulfillment, and competence unfulfillment for the French sample) still displayed acceptable levels of specificity. Interestingly, these factors were the same as those already identified as weakly-defined in the nine-factor ESEM solution (Model 7) in both samples. In addition, the 12 items with low factor loadings and/or high cross-loadings in the ninefactor ESEM solution (Model 7) also displayed, in this bifactor ESEM solution (Model 15), low factor loadings and/or at least one cross-loading higher than the target loading for the corresponding S-factor. This was the case in both samples.

Finally, the remaining key question was whether the bifactor model with three G-factors (Model 17) provided an improved representation of the data, relative to the bifactor ESEM solution which modelled a single G-factor and nine S-factors (Model 15). Results from Model 17 showed adequate fit to the data in both the English $\left(\chi^{2}(d f)=1036.293(608), \mathrm{CFI}=.962, \mathrm{TLI}=.935, \mathrm{SRMR}=.015\right.$, and RMSEA $=.045[.040 ; .050])$ and the French $\left(\chi^{2}(d f)=909.018(608)\right.$, CFI $=.974$, TLI $=.957$, SRMR $=.015$, and RMSEA $=.034[.029 ; .038]$ ) versions of the PNSW-S. Yet, in this solution, the three Gfactors were weakly defined (see the Supplementary File for further details) demonstrating against the need to incorporate three G-factors, and supporting the superiority of Model 15.

These results supported the adequacy of the bifactor ESEM solution with one G-factor and nine Sfactors (Model 15). In this solution, given that the G-factor was defined by positive loadings from need frustration and unfulfillment items, and negative loadings from the need satisfaction items, we hereafter refer to it as reflecting global levels of detrimental need states. Although the fit indices of this bifactor solution turned out to be superior in both the English-speaking and French-speaking samples, the ESEM solution with nine factors (Model 7) also proved to be an acceptable alternative. However, although these solutions seemed acceptable and superior to alternative solutions, results indicated that the psychometric properties of the PNSW-S still had room for improvement. Consequently, at this point in our research, we chose to pursue our analyses with both solutions (Models 7 and 15) in order to reach a final version of the PNSW-S before retaining one of both representations of ratings on this measure.

\section{A Shortened Version of the PNSW-S}

Based on the above-mentioned findings, we decided to remove from both the French and English 
versions of the PNSW-S the five problematic items pertaining to need satisfaction and need frustration, already identified as problematic by Bhavsar et al. (2020), and then to examine the goodness-of-fit indices and the parameter estimates of Models 7 and 15 for this 41 -item solution. It should be noted that Bhavsar et al. (2020) also removed all unfulfillment items from their analyses, because they could not find evidence to model need unfulfillment as a distinct need state, when tested together with need satisfaction and need frustration. Yet, in the present research, results did not point toward the exclusion of unfulfillment and encouraged the consideration of this third experiential state. Therefore, at this point in our research, we decided to continue with all unfulfillment items.

Results from this modified 41-item version of the PNSW-S were encouraging. In both samples, the goodness-of-fit results from both models were acceptable (see Tables S1 and S2 of the Supplementary File) and better than those of the previously tested 46-item solutions (e.g., bifactor ESEM English: $\Delta C F I$ $=+.017, \Delta \mathrm{TLI}=+.024, \Delta \mathrm{SRMR}=-.002$, and $\Delta \mathrm{RMSEA}=-.005 ;$ bifactor $\mathrm{ESEM}_{\text {French }}: \Delta \mathrm{CFI}=+.014$, $\Delta \mathrm{TLI}=+.020, \Delta \mathrm{SRMR}=-.001$, and $\Delta \mathrm{RMSEA}=-.006)$. In the English and French versions of the PNSW-S, the ESEM solution with nine factors (Model 7) resulted in seven well-defined factors and two more weakly-defined factors (factor definition is further detailed in the Supplementary File). Importantly, in both languages, this 41 -item solution was clearly better than the previous 46 -item one, because the six need satisfaction and frustration factors and the relatedness unfulfillment factor were now well-defined. Yet, it seemed that the competence and autonomy unfulfillment subscales could still be psychometrically improved, possibly by including new items.

Turning our attention to the bifactor ESEM solution with one G-factor and nine S-factors (Model 15; see Tables S4 and S6 of the Supplementary File), results from both samples revealed a welldefined G-factor with negative factor loadings associated with the need satisfaction items, and positive factor loadings associated with the need frustration and unfulfillment items. Similarly, with the exception of a few items which displayed strong target loadings on the detrimental need states Gfactor $(>.400)$ but weak target loadings on their a-priori S-factors $(<.200)$, the S-factors also retained at least some degree of meaningful specificity over and above employees' global levels of detrimental need states. Interestingly, in this 41-item version of the PNSW-S, most of these S-factors displayed higher levels of specificity than in the previous 46-item solution. In addition, model-based coefficients 
of composite reliability proved to be acceptable for this solution, except for one factor in the English version and two factors in the French version (see the Supplementary File for further details).

\section{Study 2}

Study 1 provided promising validity evidence for a multidimensional measure of employees' psychological need satisfaction, frustration, and unfulfillment, in two languages. Indeed, unlike in Bhavsar et al.'s (2020) research, we found excellent results for relatedness unfulfillment and encouraging results for the autonomy and competence unfulfillment dimensions. Because it appeared that these two dimensions could be more adequately assessed, we conducted a second study to further explore the factorial validity of the PNSW-S. Specifically, we kept the 41 items from the shortened version of the PNSW-S and added two new items to each of the two more weakly defined factors (i.e., autonomy and competence unfulfillment). These items were developed by our research team to reflect a "feeling that something is not as good as it should be" (Bartholomew et al., 2011a, p. 78) and based on definitions of what psychological needs in the workplace entail (Rigby \& Ryan, 2018). We followed precautions taken by Bhavsar et al. (2020) in writing items that were not too long, not double-barreled, did not tap into multiple needs, did not refer explicitly to the social context, and did not borrow heavily from existing measures. Ultimately, our goal was to re-test whether the (bifactor) ESEM structures, which proved to be superior in both samples in Study 1, would remain the most adequate in a new sample.

This study also aimed to provide initial evidence for the criterion-related validity of this final version of the PNSW-S. In line with SDT's propositions, we hypothesized that need satisfaction would be best predicted by supportive behaviors and, in turn, relate more strongly to job satisfaction (Bhavsar et al., 2019; Gillet et al., 2012a). In contrast, we expected need frustration, and to a lesser extent need unfulfillment, to be best predicted by thwarting behaviors (Bhavsar et al., 2019; Gillet et al., 2012a). In turn, we hypothesized that need frustration would associate more strongly to emotional exhaustion, while need unfulfillment would display stronger associations with job boredom.

\section{Method}

\section{Procedure}

Participants were recruited via Prolific Academic using the same procedures and inclusion criteria 
as in Study 1. The offered compensation to complete this 10-minute questionnaire was $£ 1.00$. A total of 27 attention checks were failed and linked to 23 respondents who were excluded from the sample.

\section{Participants}

A total of 450 participants $\left(M_{\text {age }}=37.74 ; S D=10.87\right)$ completed the survey. Most of them were women (50.4\%), $48.7 \%$ were men, and $0.9 \%$ identified as non-binary. Participants lived and worked either in the United Kingdom (64\%), in the United States of America (32.4\%), or in Canada (3.6\%). Most of the participants worked under a permanent contract (90.9\%), while 6.7\% had a fixed-term contract, and $2.4 \%$ had other types of contract (e.g., zero-hour contract). Participants had been working in their current job position for 5.74 years on average $(S D=5.29)$ and under the supervision of their current supervisor for 3.98 years on average $(S D=3.86)$, while a substantial proportion of the participants supervised a team themselves (44.4\%). Most of the respondents worked full-time $(82.2 \%)$ and, on average, 36.65 hours a week $(S D=8.93)$. Participants mostly worked in the private sector (64.2\%), namely, in non-market services (45.1\%), market services (37.6\%), industry (10.4\%), and construction (4.9\%), while $2 \%$ did not know under which of these areas their job fell.

\section{Measures}

Supportive behaviors were measured with an 8 -item subscale $(\alpha=.95$; e.g., competence support, "explains the reasons when he/she asks me to do something") from the Tripartite Measure of Interpersonal Behaviors-Supervisor (TMIB-S; Huyghebaert-Zouaghi et al., 2020b), adapted from Bhavsar et al. (2019). Prior research established the validity of this measure (Huyghebaert-Zouaghi et al., 2020b). Workers were asked to consider their experience with their current supervisor to indicate the extent to which they agreed with each statement using a scale ranging from 1 (strongly disagree) to 7 (strongly agree).

Thwarting behaviors were measured with an 8 -item subscale $(\alpha=.94$; e.g., relatedness thwarting, "makes it clear that he/she doesn't like me") from the TMIB-S (Huyghebaert-Zouaghi et al., 2020b), using the same scales and anchors as those given for supportive behaviors. Recent studies demonstrated the validity of this measure (Huyghebaert-Zouaghi et al., 2020b).

Psychological Need States were measured with the modified 41-item English version of the PNSW-S resulting from Study 1, to which we added two new autonomy unfulfillment (i.e., “...I often 
do not understand the rationale behind the tasks that I have to realize" [aU6] and "...I often do not understand the rationale for how my job is expected to be done" [aU7]) and two new competence unfulfillment items (“...generally, I am not satisfied with my performance” [cU6] and “...I usually feel like I am not very useful" [cU7]). Before completing this 45-item scale, workers were asked to consider their general experience in their current job to indicate the extent to which they agreed with each statement (1-strongly disagree to 7-strongly agree). Twelve items measured need satisfaction ( $\alpha$ $=.95)$ : Three items for autonomy $(\alpha=.90)$, three for competence $(\alpha=.84)$, and six for relatedness $(\alpha=$ .96). Fourteen items measured need frustration ( $\alpha=.95)$ : Four items for autonomy $(\alpha=.87)$, four for competence $(\alpha=.93)$, and six for relatedness $(\alpha=.94)$. Nineteen items measured need unfulfillment $(\alpha$ $=.94)$ : Seven items for autonomy $(\alpha=.89)$, seven for competence $(\alpha=.86)$, and six for relatedness $(\alpha$ $=.92)$.

Job satisfaction was assessed with a single-item measure (Nagy, 2002; Wanous et al., 1997) asking participants to indicate the extent to which they were satisfied with their current job (1dissatisfied to 4-satisfied). Prior research has provided evidence for the validity of a single-item measure of job satisfaction (e.g., Shimazu et al., 2015), including in relation to psychological needs (Huyghebaert-Zouaghi et al., 2020a).

Job boredom was measured with the Dutch Boredom Scale (DUBS; Reijseger et al., 2013). These six items ( $\alpha=.86$; e.g., "I feel bored at my job") were rated on a five-point scale ( $1-$ never to $5-$ always) whose validity was demonstrated in previous research (e.g., Harju et al., 2018).

Work-related rumination was assessed with two items ( $\alpha=.83$; de Bloom et al., 2014) asking employees to indicate their level of agreement with each statement (e.g., "I ruminate about things that have happened at work") by rating their responses on a scale from 1 (strongly disagree) to 5 (strongly agree). The validity of this measure was supported by prior studies (e.g., de Bloom et al., 2014).

\section{Analyses}

As in Study 1, a series of 17 CFA and ESEM models were tested using the same procedures. Criterion validity analyses were then conducted. The predictor (perceptions of supervisors' supportive and thwarting behaviors) and outcome (job boredom and work-related rumination) variables were specified as fully latent factors. Job satisfaction, assessed with a single item, was also predicted by the 
different components of psychological need states.

\section{Results}

As in Study 1, only three solutions were able to achieve an acceptable level of fit to the data (Models 7, 15, and 17). However, an examination of the parameter estimates associated with Model 17 revealed that the correlations observed between the three G-factors were so high so as to call into question the discriminant validity of these factors $(|r|=.732$ to $.867, M=.783)$. This pattern was indicative of evidence arguing against the need to incorporate three G-factors, as in Study 1.

\section{Final Version of the PNSW-S}

As in Study 1, the ESEM solution with nine factors (Model 7) resulted in two weakly-defined factors, namely autonomy and competence unfulfillment. Interestingly, the six items in these two factors which proved to be problematic here (i.e., low factor loadings and/or high cross-loadings) were also found to be problematic in Study 1, but were then kept for further testing. Because these results supported those from Study 1, these six items were thus removed (aU1, aU3, aU4, cU1, cU4, cU5). Moreover, one of the two newly added competence unfulfillment items also turned out to be problematic (cU7), and was, therefore, also removed. Finally, one item in the relatedness frustration factor (rF6) had a low factor loading (.282) and was also removed, as this item already also had a low factor loading in Study 1 (.293). The resulting 37-item and final version of the PNSW-S (see Appendix) showed adequate fit to the data: $\chi^{2}(d f)=757.983$ (369), CFI $=.964$, TLI $=.936$, SRMR $=$ .014 , and RMSEA $=.048$ [.043; .053]. In this nine-factor ESEM solution (Model 7), based on 37 items, all factors were well-defined (see the Supplementary File for further details). Although this ESEM solution did incorporate multiple statistically significant cross-loadings, none of these crossloadings was large enough to suggest a problem in terms of factor definition $((|\lambda|=.001$ to $.336, M=$ .080): All cross-loadings were under .350 and lower than the target loadings.

The goodness-of-fit associated with the bifactor ESEM solution (Model 15) appeared to be adequate and higher than that of the ESEM solution (Model 7): $\chi^{2}(d f)=586.954(341), \mathrm{CFI}=.978$, $\mathrm{TLI}=.956, \mathrm{SRMR}=.013$, and RMSEA $=.040[.035 ; .045]$. In addition, results revealed a welldefined G-factor with negative factor loadings associated with the need satisfaction items, and positive factor loadings associated with the need frustration and unfulfillment items (see Table S8 of the 
Supplementary File). Similarly, except for a few items which presented strong target loadings on the detrimental need states G-factor (>.400) but weak target loadings on their a-priori S-factors $(<.200)$, the S-factors also retained at least some degree of meaningful specificity over and above employees' global levels of detrimental need states (see the Supplementary File for further details). Although this bifactor ESEM solution did incorporate multiple statistically significant cross-loadings, none of these cross-loadings was large enough to suggest a problem in terms of factor definition $(|\lambda|=.002$ to .275 , $M=.061)$ : All cross-loadings were under .300 and lower than the target loadings.

Comparison of the parameter estimates associated with Models 7 and 15, which are reported in Tables S7 and S8 of the Supplementary File, supported the superiority of the bifactor ESEM solution (Model 15). More precisely, both solutions resulted in well-defined factors but it is noteworthy that observing that the multiple cross-loadings in ESEM were reduced in bifactor ESEM is a source of evidence in favor of the bifactor solution (Morin et al., 2016a). Nonetheless, both the ESEM (Model 7) and bifactor ESEM (Model 15) representations proved to be adequate. Because both these representations of psychological need states proved to be valid, a decision had to be made to retain one or the other for further analyses that explored associations with criterion variables. We considered several methodological and conceptual factors.

On one hand, the bifactor ESEM approach is more psychometrically fine-grained as it allows to reflect the commonalities shared by need states while reflecting what is unique and specific to each distinctive need state. However, on the other hand, because S-factors reflect residual scores (i.e., what remains once the shared variance between all items has been extracted and reflected in the G-factor), they have a different conceptual underpinning than the one covered by the more typical first-order factors usually studied (e.g., Cheon et al., 2019). Moreover, the importance of the global factor in bifactor representations of psychological needs (Gillet et al., 2019; Huyghebaert-Zouaghi et al., 2020a; Sánchez-Oliva et al., 2017) limits the possibility to explore the effects associated with the specific factors. Indeed, the criteria's variability explained by the specific factors reflects what is unaccounted for by the global factor.

In sum, the bifactor solution (Model 15) was psychometrically more robust and rigorous. Yet, because of the statistical complexity of this approach and because the exact conceptual nature of the 
specific factors once their shared commonalities are extracted remains to be further explored (Litalien et al., 2017), we chose to pursue our analyses with the more parsimonious ESEM solution (Model 7), which appears to be more conceptually consistent with SDT (Bhavsar et al., 2020). Predictive results associated with the bifactor ESEM solution are reported in the Supplementary File.

\section{Predictive Models}

The goodness-of-fit indices from the predictive model were satisfactory for the ESEM solution: $\chi^{2}$ $(d f)=3015.376(1521), \mathrm{CFI}=.925, \mathrm{TLI}=.907$, and RMSEA $=.047[.044 ; .049]$. Comparisons of parameter estimates revealed statistically significant effects of the predictors (supervisors' interpersonal behaviors) on psychological need states, and of psychological need states on the outcomes (job boredom, rumination, and job satisfaction). These results are reported in Table 1.

Results first revealed that supportive behaviors were associated with higher levels of relatedness satisfaction and autonomy satisfaction, and lower levels of relatedness unfulfillment, autonomy unfulfillment, and competence unfulfillment. In contrast, thwarting behaviors were associated with lower levels of relatedness satisfaction and autonomy satisfaction, and higher levels of relatedness frustration, autonomy frustration, competence frustration, relatedness unfulfillment, and autonomy unfulfillment. Moreover, relatedness satisfaction and frustration were associated with higher levels of job satisfaction. In contrast, competence frustration, relatedness unfulfillment, and competence unfulfillment were associated with lower levels of job satisfaction. Autonomy frustration was associated with higher levels of rumination. Finally, relatedness satisfaction was associated with lower levels of boredom, while relatedness unfulfillment was associated with higher levels of boredom.

\section{Discussion}

The present work aimed to further extend previous theoretical developments in the SDT literature on psychological needs (Cheon et al., 2019; Costa et al., 2015) and to address the absence of a workspecific measure which jointly examines the experiential states of satisfaction, frustration, and unfulfillment of the needs for autonomy, competence, and relatedness.

\section{From Two to Three Need States}

Via two studies and three distinct samples of employees, we provided evidence to demonstrate that the unfulfillment of the needs for autonomy, competence, and relatedness could be modeled as a 
distinct need state when tested alongside the satisfaction and frustration of those three needs. In other words, our results supported the 3 x 3 conceptual model of psychological need states depicted in Figure 1. In doing so, our research deepens our understanding of the nature of psychological need states in the workplace by showing that, in this life domain, individuals' psychological needs are not experienced in a dichotomous manner, through the beneficial and adverse experiences of need satisfaction and frustration, respectively. Rather, employees may also undergo a more nuanced and less actively negative psychological experience characterized by uncertainty, dullness, and disconnection, in the form of need unfulfillment.

Building upon Bhavsar et al. (2020), we provided validity evidence for the final 37-item version PNSW-S to measure these distinct experiential states (12 items measuring need satisfaction, 13 items measuring need frustration, and 12 items for need unfulfillment; see Appendix). In doing so, we expanded existing measures of work-related psychological need states (Brien et al., 2012; Deci et al., 2001; Gillet et al., 2012b; Van den Broeck et al., 2010) by offering a multidimensional instrument allowing to simultaneously assess not only need satisfaction and frustration, but also need unfulfillment. Indeed, because these need states are distinct experiences which can co-occur within a given context over time (Costa et al., 2015), it seemed important to provide researchers and practitioners with a tool to jointly assess all three need states. By showing that the psychological need states experienced by employees can be expanded and by providing a tool to measure these distinct need states, our research opens up new horizons for SDT researchers to further shed light on these experiential states in the workplace, and to explore their relevance in other life domains.

\section{Multidimensionality of Psychological Need States}

Results from Studies 1 and 2 showed that both ESEM (nine factors) and bifactor ESEM (one Gfactor and nine S-factors) representations of psychological need states ratings on the PNSW-S are adequate and may thus both be used by researchers and practitioners. Importantly, it should be noted that the identification of a "vanishing" (i.e., a S-factor left with no meaningful specificity once the global levels are considered) - or at least weakly defined-S-factor appears to be the norm in prior studies in which a bifactor operationalization of psychological need states was adopted (e.g., Gillet et al., 2019; Huyghebaert-Zouaghi et al., 2020a; Sánchez-Oliva et al., 2017). Yet, in our research, no 
vanishing factor was identified, which is a strength suggesting that each specific experiential state (satisfaction, frustration, and unfulfillment) pertaining to the needs for autonomy, competence, and relatedness retained sufficient specificity over and above the global factor.

\section{Antecedents and Consequences of Psychological Need States}

Based on a nine-factor ESEM representation of psychological need states, our study provided initial evidence for the criterion-related validity of the PNSW-S.

\section{Supervisory Behaviors and Psychological Need States}

We provided a first in the literature exploration of the work-related socio-contextual antecedents of the three psychological need states. This examination resulted in a total of 12 (out of 18 specified associations) significant and well-differentiated associations between perceived supervisory behaviors and the distinct psychological need states. Interestingly, we demonstrated that the distinct need states stem from distinct experiences that employees may have at work, with need satisfaction being best predicted by supervisors' supportive behaviors, need frustration arising more strongly from supervisors' thwarting behaviors, and need unfulfillment relating to both types of socio-contextual antecedents. We discuss below how these results contribute to the SDT literature.

Specifically, results showed that perceived supportive behaviors from one's supervisor best predicted higher levels of need satisfaction (autonomy and relatedness), and to a lesser extent, lower levels of need unfulfillment (autonomy, competence, and relatedness), yet they did not significantly associate with need frustration. These results corroborate prior SDT research which showed autonomy support to relate more strongly to need satisfaction (Bartholomew et al., 2011b; Gillet et al., 2012a), and even reinforce these past findings by demonstrating that supportive behaviors share no significant association with need frustration. Contrastingly, thwarting behaviors best predicted higher levels of need frustration (autonomy, competence, and relatedness), and to a lesser extent, more unfulfillment and less satisfaction of the needs for autonomy and relatedness. These results are consistent with findings from SDT showing need thwarting behaviors to best predict need frustration while controlling for need satisfaction (Bhavsar et al., 2019; Gillet et al., 2012a). Altogether, these results extend SDT, as they are first to consider supervisors' supportive and thwarting behaviors toward all three needs (Bhavsar et al., 2019; Rocchi et al. 2017a, 2017b; Toth-Kiraly et al., 2020), rather than solely 
autonomy.

Importantly, our research contributes to SDT as it is the first to shed light on the socio-contextual antecedents of need unfulfillment, across all three needs (Cheon et al., 2019; Costa et al., 2015). Specifically, need unfulfillment appeared to be rather equally predicted by both supportive (negatively) and thwarting behaviors (positively), hence, no clear conclusion can be drawn as to whether need unfulfillment stems more from the former or the latter form of interpersonal behaviors. These results could suggest that need unfulfillment may stem from a different form of interpersonal behaviors. Interestingly, recent research conducted in the sport and work domains (Bhavsar et al., 2019; Huyghebaert-Zouaghi et al., 2020b) demonstrated indifferent behaviors (i.e., leaders are inattentive to the basic psychological needs of those they guide) to be a third and distinct form of interpersonal behaviors, when tested alongside supportive and thwarting behaviors. Need unfulfillment might thus be best predicted by such indifferent and neglectful behaviors (Bhavsar et al., 2019; Cheon et al., 2019; Huyghebaert-Zouaghi et al., 2020b), rather than by supportive or thwarting behaviors.

\section{Psychological Need States and Employees' Functioning}

Our research offered a first exploration of the associations between autonomy, competence, relatedness satisfaction, frustration, and unfulfillment on one hand, and job satisfaction, work-related rumination, and job boredom on the other hand. Although in Study 2, only a third of the specified associations turned out to be significant ( 8 out of 27), our approach has the merit of providing an indepth portrayal of the relative importance of each psychological need state in relation to various indicators of employees' functioning (Fernet et al., 2012; Trépanier et al., 2016). Indeed, the identified significant associations demonstrated that the distinctive need states had well-differentiated effects in terms of employee functioning.

Results showed work-related rumination to be predicted by need frustration, while need satisfaction and need unfulfillment held no significant association with this adverse outcome. Specifically, workrelated rumination was predicted by the frustration of employees' need for autonomy, thus showing that it is the psychological experience of feeling coerced at work that has the power to spill over to employees' personal time in the form of recurring and invasive thoughts about this adverse experience. This result corroborates the importance of the need for autonomy, which is thought to be 
"most unique to SDT" (Vansteenkiste et al., 2020, p. 14). Contrastingly, job satisfaction was more strongly predicted, in the expected direction, by need satisfaction than by other need states. Specifically, results indicated that it was the satisfaction of employees' need for relatedness that contributed the most to their positive evaluation of their work experience (Locke, 1976). Surprisingly, relatedness frustration also predicted higher levels of job satisfaction, yet this association was less significant and weaker than the one between relatedness satisfaction and job satisfaction. Still, this may suggest that when they feel rejected and despised at work, employees may focus on other -non relational- facets of their job satisfaction (e.g., work itself, pay, opportunities for promotion) to assess their general experience in their job (Nagy, 2002). Finally, lower levels of job satisfaction were also predicted by competence frustration and unfulfillment as well as relatedness unfulfillment, yet these associations were much weaker than the one between relatedness satisfaction and job satisfaction, which is line with prior findings (Cheon et al., 2019; Gillet et al., 2012a). Altogether, these results provided further evidence for SDT findings showing need satisfaction and need frustration to be distinct constructs, with need satisfaction dimensions best predicting work-related indicators of wellbeing (Huyghebaert et al., 2018a; Trépanier et al., 2015), and need frustration facets mainly predicting indices of ill-being at work (Huyghebaert et al., 2018b; Trépanier et al., 2015).

Importantly, job boredom, which also constitutes an indicator of ill-being but not as adverse as work-related rumination, was best predicted by need unfulfillment. Specifically, results showed that it was the unfulfillment of employees' need for relatedness that predicted job boredom, thus suggesting that relational aspects are key in giving employees the feeling that their work environment is not as stimulating as it should be. Interestingly, job boredom has been proposed to stem from an inadequately stimulating and challenging work situation in terms of tasks and activities (Schaufeli \& Salanova, 2014). Yet, our results show that it may also stem from an inadequately stimulating environment in terms of interactions (i.e., when employees experience no meaningful connection with their work peers; relatedness unfulfillment). This finding thus opens new research perspectives regarding the antecedents of job boredom, especially as many workplaces tend to evolve toward remote and virtual teams (Kniffin et al., 2020), where employees may lack opportunities for informal and meaningful interactions with coworkers and thus perceive their job as inadequately stimulating socially. 
Finally, we contributed to SDT by providing support for the idea that need frustration and unfulfillment dimensions predict maladaptive outcomes that differ in nature (Cheon et al., 2019), with need frustration facets better predicting actively adverse outcomes (work-related rumination) and need unfulfillment dimensions better predicting passive forms of maladaptive functioning (boredom). In other words, we showed that need unfulfillment is not as adverse an experience as need frustration is, yet it still yields negative outcomes. These results may more generally contribute to research on the mechanisms through which the work environment influences employees' functioning (Huyghebaert et al., 2018a, 2018b; Trépanier et al., 2015). Hence, these results may suggest the existence of a passively deleterious pathway: A health eroding process which could constitute an alternative process, less serious than the health impairment process, yet more concerning than the motivational process proposed in the job demands-resources model (Bakker \& Demerouti, 2017).

\section{Limitations and Directions for Future Research}

Although this research offered empirical support for recent conceptual developments in the psychological needs literature, epitomized in our proposed 3 x 3 model of psychological need states, it has some limitations. First, we did not provide validity evidence for the final version of the PNSW-S in the French language. Although results regarding the French and English versions were comparable in Study 1 and one could thus expect the factorial structure of the English version of the PNSW-S found in Study 2 to replicate in a French speaking sample, a new study would be needed to corroborate this prediction. Indeed, in Study 1, one item (rS5) displayed a low factor loading in the 41item French version (see Table S5 of the Supplementary File). Yet, because this item proved to be acceptable in the English version (in both Studies 1 and 2), and because it was not removed by Bhavsar et al. (2019), we did not have enough theoretical or empirical support to remove this item from the French version at this point in our research. More testing of the French version of the PNSW$\mathrm{S}$ is clearly needed in order to confirm whether this item can be retained in the French version.

Demonstrating the invariance of the final version of the PNSW-S across different languages and countries could make it a valuable tool for researchers and practitioners (Vandenberg \& Lance, 2000).

Second, research could test the generalizability of the multidimensionality of psychological need states -particularly need unfulfillment- as well as of their associations with outcomes. Indeed, we 
relied on three samples of workers from western cultures (France, UK, US, and Canada), thus not being able to provide evidence about the extent to which our results could generalize to additional cultural or linguistic groups. Moreover, we were not able to collect race, ethnicity, and socioeconomic status of the samples, some caution is thus warranted when interpreting our results, until more evidence of invariance across distinct racial, ethnic, and socioeconomic groups can be provided. This is of particular importance for future research to address, as the universality of psychological needs is a key criterion of SDT (Vansteenkiste et al., 2020). Third, although Study 2 displayed welldifferentiated associations between need states and outcomes (in the expected direction), further criterion validity evidence could be offered by considering different indices of psychological health. Indeed, extending the nomological network of need states may result in more significant and stronger associations. Moreover, we relied on self-report measures, which may have been impacted by social desirability and self-report biases. Future research could use more objective indicators of individual functioning (e.g., psychobiolological markers of stress; Bartholomew et al., 2011b).

Fourth, future research would benefit from longitudinal designs allowing for a more precise investigation of the temporal effects of psychological need states. In this paper we used the terms "antecedents" and "consequences" to refer to variables that have been conceptualized as such in the SDT literature, but we acknowledge that these variables, over time, can be outcomes and antecedents, respectively, of psychological need states. Fifth, in this research, we solely considered supportive and thwarting behaviors as antecedents of psychological needs, yet, it would be interesting to explore how supervisors' indifferent behaviors (Bhavsar et al., 2019) relate to all three experiential need states. Finally, we relied on a variable-centered approach, yet, by examining average relations occurring among variables in a specific sample, these analyses ignore the possible existence of subpopulations among which these relations could differ. In contrast, person-centered analyses allow for the identification of qualitatively distinct subgroups of employees characterized by different configurations of psychological need states (Huyghebaert-Zouaghi et al., 2020a). Future research could pursue this avenue to identify the most optimal combinations of psychological need states, as well as their antecedents and their implications in terms of employees' functioning.

Despite these limitations, the present research adds to the literature by emphasizing the utility of 
considering not just the bright (need satisfaction) and the dark side (need frustration) of psychological need states, but also a distinctive grey zone (need unfulfillment) that is not covered by these two experiences. These results thus indicate that SDT's explanatory framework can be expanded from two (Bartholomew et al., 2011b) to three need processes to explain the effect of the socio-contextual environment on employee functioning.

\section{References}

Asparouhov, T., Múthen, B., \& Morin, A.J.S. (2015). Bayesian structural equation modeling with cross-loadings and residual covariances. Journal of Management, 41, 1561-1577.

Bakker, A.B., \& Demerouti, E. (2013). The spillover-crossover model. In J. Grzywacz, \& E. Demerouti (Eds.). New Frontiers in Work and Family Research, pp. 54-70.

Bartholomew, K.J., Ntoumanis, N., Cuevas, R., \& Lonsdale, C. (2014). Job pressure and ill-health in physical education teachers: The mediating role of psychological need thwarting. Teaching and Teacher Education, 37, 101-107.

Bartholomew, K.J., Ntoumanis, N., Ryan, R.M., \& Thøgersen-Ntoumani, C. (2011a). Psychological need thwarting in the sport context: Assessing the darker side of athletic experience. Journal of Sport \& Exercise Psychology, 33, 75-102.

Bartholomew, K.J., Ntoumanis, N., Ryan, R.M., Bosch, J.A., \& Thøgersen-Ntoumani, C. (2011b). Self-determination theory and dimin- ished functioning: The role of interpersonal control and psychological need thwarting. Personality and Social Psychology Bulletin, 37, 1459-1473.

Bhavsar, N., Bartholomew, K.J., Quested, E., Gucciardi, D.F., Thøgersen-Ntoumani, C., Reeve, J., ... \& Ntoumanis, N. (2020). Measuring psychological need states in sport: Theoretical considerations and a new measure. Psychology of Sport and Exercise, 47, 101617.

Bhavsar, N., Ntoumanis, N., Quested, E., Gucciardi, D.F., Thøgersen-Ntoumani, C., Ryan, R.M., ... \& Bartholomew, K.J. (2019). Conceptualizing and testing a new tripartite measure of coach interpersonal behaviors. Psychology of Sport and Exercise, 44, 107-120.

Bidee, J., Vantilborgh, T., Pepermans, R., Griep, Y., \& Hofmans, J. (2016). Temporal dynamics of need satisfaction and need frustration. Two sides of the same coin?. European Journal of Work and Organizational Psychology, 25, 900-913. 
Brien, M., Forest, J., Mageau, G.A., Boudrias, J.S., Desrumaux, P., Brunet, L., \& Morin, E.M. (2012). The basic psychological needs at work scale: measurement invariance between Canada and France. Applied Psychology: Health and Well-Being, 4, 167-187.

Browne, M.W. (2001). An overview of analytic rotation in exploratory factor analysis. Multivariate Behavioral Research, 36, 111-150.

Cheon, S.H., Reeve, J., Lee, Y., Ntoumanis, N., Gillet, N., Kim, B.R., \& Song, Y.-G. (2019). Expanding autonomy psychological need states from two (satisfaction, frustration) to three (dissatisfaction): A classroom-based intervention study. Journal of Educational Psychology, 11, $685-702$.

Costa, S., Ntoumanis, N., \& Bartholomew, K. (2015). Predicting the brighter and darker sides of interpersonal relationships: Does psychological need thwarting matter? Motivation and Emotion, $39,11-24$.

de Bloom, J., Radstaak, M., \& Geurts, S. (2014). Vacation effects on behaviour, cognition and emotions of compulsive and non-compulsive workers: Do obsessive workers go 'cold Turkey'? Stress and Health, 30, 232-243.

Deci, E.L., \& Ryan, R.M. (2000). The" what" and" why" of goal pursuits: Human needs and the selfdetermination of behavior. Psychological Inquiry, 11, 227-268.

Deci, E.L., \& Ryan, R.M. (2008). Self-determination theory: A macro theory of human motivation, development, and health. Canadian Psychology, 49, 182-185.

Deci, E.L., Ryan, R.M., Gagne, M., Leone, D.R., Usunov, J., \& Kornazheva, B.P. (2001). Need satisfaction, motivation, and well-being in the work organizations of a former Eastern Bloc country: A cross-cultural study of self-determination. Personality and Social Psychology Bulletin, $27,930-942$.

Fernet, C., Austin, S., Trépanier, S.G., \& Dussault, M. (2013). How do job characteristics contribute to burnout? Exploring the distinct mediating roles of perceived autonomy, competence, and relatedness. European Journal of Work and Organizational Psychology, 22, 123-137. 
Gillet, N., Fouquereau, E., Forest, J., Brunault, P., \& Colombat, P. (2012a). The impact of organizational factors on psychological needs and their relations with well-being. Journal of Business and Psychology, 27, 437-450.

Gillet, N., Fouquereau, E., Lequeurre, J., Bigot, L., \& Mokounkolo, R. (2012b). Validation of a scale to measure psychological need thwarting at work (EFBPT). Psychologie du Travail et des Organisations, 18, 328-344.

Gillet, N., Morin, A.J.S., Choisay, F., \& Fouquereau, E. (2019). A person-centered representation of basic need satisfaction balance at work. Journal of Personnel Psychology, 18, 113-128.

Gillet, N., Morin, A.J.S., Huart, I., Colombat, P., \& Fouquereau, E. (2020). The forest and the trees: Investigating the globality and specificity of employees' basic need satisfaction at work. Journal of Personality Assessment, 102, 702-713.

Gillet, N., Rosnet, E., \& Vallerand, R.J. (2008). Développement d'une échelle de satisfaction des besoins fondamentaux en contexte sportif [Development of a scale of satisfaction of the fundamental requirements in sporting context]. Canadian Journal of Behavioural Science, 40, 230-237.

Harju, L.K., Schaufeli, W.B., \& Hakanen, J.J. (2018). A multilevel study on servant leadership, job boredom and job crafting. Journal of Managerial Psychology, 33, 2-14.

Hu, L.-T., \& Bentler, P.M. (1999). Cutoff criteria for fit indexes in covariance structure analysis: Conventional criteria versus new alternatives. Structural Equation Modeling, 6, 1-55.

Huyghebaert, T., Gillet, N., Fernet, C., Lahiani, F.J., \& Fouquereau, E. (2018a). Leveraging psychosocial safety climate to prevent ill-being: The mediating role of psychological need thwarting. Journal of Vocational Behavior, 107, 111-125.

Huyghebaert, T., Gillet, N., Fernet, C., Lahiani, F.J., Chevalier, S., \& Fouquereau, E. (2018b). Investigating the longitudinal effects of surface acting on managers' functioning through psychological needs. Journal of Occupational Health Psychology, 23, 207-222.

Huyghebaert-Zouaghi, T., Morin, A.J.S., Forest, J., Fouquereau, E., \& Gillet, N. (2020a). A longitudinal examination of nurses' need satisfaction profiles: A latent transition analysis. Current Psychology. Advance online publication. doi: 10.1007/s12144-020-00972-1 
Huyghebaert-Zouaghi, T., Morin, A. J. S, Ntoumanis, N., Berjot, S., \& Gillet, N. (2020b). Leaders' interpersonal styles: A new full-range conceptualization and measure based on SelfDetermination Theory. Manuscript submitted for publication.

Jang, H., Reeve, J., Ryan, R.M., \& Kim, A. (2009). Can self-determination theory explain what underlies the productive, satisfying learning experiences of collectivistically oriented Korean students? Journal of Educational Psychology, 101, 644-661.

Keyes, C.L. (2005). Mental illness and/or mental health? Investigating axioms of the complete state model of health. Journal of Consulting and Clinical Psychology, 73, 539-548.

Kniffin, K.M., Narayanan, J., Anseel, F., Antonakis, J., Ashford, S.J., Bakker, A.B., ... \& Creary, S.J. (2020). COVID-19 and the workplace: Implications, issues, and insights for future research and action. American Psychologist. Advance online publication. doi: 10.1037/amp0000716

Litalien, D., Morin, A.J.S, Gagné, M., Vallerand, R.J., Losier, G.F., \& Ryan, R.M. (2017). Evidence of a continuum structure of academic self-determination: A two-study test using a bifactor-ESEM representation of academic motivation. Contemporary Educational Psychology, 51, 67-82.

Locke, E. (1976). The nature and causes of job satisfaction. In M. D. Dunnette (Eds.), Handbook of industrial and organizational psychology (pp. 1297-1349). Chicago, IL: Rand McNally.

Lu, H., Zhao, Y., \& While, A. (2019). Job satisfaction among hospital nurses: A literature review. International Journal of Nursing Studies, 94, 21-31.

Lyubomirsky, S., \& Tkach, C. (2003). The consequences of dysphoric rumination. In C. Papageorgiou \& A. Wells (Eds.), Rumination: Nature, theory, and treatment of negative thinking in depression (pp. 21-41). Chichester, England: John Wiley \& Sons

Mai, Y., Zhang, Z., \& Wen, Z. (2018). Comparing exploratory struc- tural equation modeling and existing approaches for multiple regression with latent variables. Structural Equation Modeling, $25,479-737$.

Marsh, H.W., Hau, K., \& Grayson, D. (2005). Goodness of fit in structural equation models. In A. Maydeu-Olivares \& J. J. McArdle (Eds.), Contemporary psychometrics (pp. 275-340). Mahwah, NJ: Erlbaum.

Martin, L.L., \& Tesser, A. (1996). Some ruminative thoughts. Advances in Social Cognition, 9, 1-47. 
Meyer, J.P., \& Morin, A.J.S. (2016). A person-centered approach to commitment research: Theory, research, and methodology. Journal of Organizational Behavior, 37, 584-612.

Mikulas, W.L., \& Vodanovich, S.J. (1993). The essence of boredom. The Psychological Record, 43, 3-12.

Moreau, E., \& Mageau, G.A. (2012). The importance of perceived autonomy support for the psychological health and work satisfaction of health professionals: Not only supervisors count, colleagues too!. Motivation and Emotion, 36, 268-286.

Morin, A.J.S., Arens, A.K., \& Marsh, H.W. (2016a). A bifactor exploratory structural equation modeling framework for the identification of distinct sources of construct-relevant psychometric multidimensionality. Structural Equation Modeling, 23, 116-139.

Morin, A.J.S, Meyer, J.P., Creusier, J., \& Biétry, F. (2016b). Multiple-group analysis of similarity in latent profile solutions. Organizational Research Methods, 19, 231-254.

Morin, A.J.S., Boudrias, J.-S., Marsh, H.W., McInerney, D.M., Dagenais-Desmarais, V., Madore, I., \& Litalien, D. (2017). Complementary variable- and person-centered approaches to exploring the dimensionality of psychometric constructs: Application to psychological wellbeing at work. Journal of Business \& Psychology, 32, 395-419.

Muthén, L.K., \& Muthén, B. (2018). Mplus user's guide. Los Angeles: Muthén \& Muthén.

Nagy, M.S. (2002). Using a single-item approach to measure facet job satisfaction. Journal of Occupational and Organizational Psychology, 75, 77-86.

Neubauer, A.B., \& Voss, A. (2018). The structure of need fulfillment: Separating need satisfaction and dissatisfaction on between- and within-person level. European Journal of Psychological Assessment, 34, 220-228.

Olafsen, A.H., \& Deci, E.L. (2020). Self-determination theory and its relation to organizations. In Oxford Research Encyclopedia of Psychology, Methods and Approaches in Psychology, Organizational and Institutional Psychology. doi: 10.1093/acrefore/9780190236557.013.112

Palan, S., \& Schitter, C. (2018). Prolific. ac—A subject pool for online experiments. Journal of Behavioral and Experimental Finance, 17, 22-27. 
Peer, E., Brandimarte, L., Samat, S., \& Acquisti, A. (2017). Beyond the Turk: Alternative platforms for crowdsourcing behavioral research. Journal of Experimental Social Psychology, 70, 153-163.

Reijseger, G., Schaufeli, W.B., Peeters, M.C., Taris, T.W., Van Beek, I., \& Ouweneel, E. (2013). Watching the paint dry at work: Psychometric examination of the Dutch Boredom Scale. Anxiety, Stress \& Coping, 26, 508-525.

Reise, S.P. (2012). The rediscovery of bifactor measurement models. Multivariate Behavioral Research, 47, 667-696.

Rigby, C.S., \& Ryan, R.M. (2018). Self-determination theory in human resource development: New directions and practical considerations. Advances in Developing Human Resources, 20, 133-147.

Rocchi, M., Pelletier, L., \& Desmarais, P. (2017a). The validity of the interpersonal behaviours questionnaire (IBQ) in sport. Measurement in Physical Education and Exercise Science, 21, 15.

Rocchi, M., Pelletier, L., Cheung, S., Baxter, D., \& Beaudry, S. (2017b). Assessing need-supportive and need-thwarting interpersonal behaviours: The Interpersonal Behaviours Questionnaire (IBQ). Personality and Individual Differences, 104, 423-433.

Ryan, R.M., \& Deci, E.L. (2017). Self-determination theory: Basic psychological needs in motivation, development, and wellness. New-York, NY: Guilford Publications.

Sánchez-Oliva, D., Morin, A.J.S, Teixeira, P.J., Carraça, E.V., Palmeira, A.L., \& Silva, M.N. (2017). A bifactor exploratory structural equation modeling representation of the structure of the basic psychological needs at work scale. Journal of Vocational Behavior, 98, 173-187.

Schaufeli, W.B., \& Salanova, M. (2014). Burnout, boredom, and engagement in the workplace. In M.C.W. Peeters, J. de Jonge, \& T.W. Taris (Eds), An introduction to contemporary work psychology (pp. 293-320). Chichester, UK: John Wiley \& Sons.

Schultz, P.P., Ryan, R.M., Niemiec, C.P., Legate, N., \& Williams, G.C. (2015). Mindfulness, work climate, and psychological need satisfaction in employee well-being. Mindfulness, 6, 971-985.

Shimazu, A., Schaufeli, W.B., Kamiyama, K., \& Kawakami, N. (2015). Workaholism vs. work engagement: The two different predictors of future well-being and performance. International Journal of Behavioral Medicine, 22, 18-23. 
Slemp, G.R., Kern, M.L., Patrick, K.J., \& Ryan, R.M. (2018). Leader autonomy support in the workplace: A meta-analytic review. Motivation and Emotion, 42, 706-724.

Tóth-Király, I., Morin, A.J.S., Bőthe, B., Orosz, G., \& Rigó, A. (2018). Investigating the multidimensionality of need fulfillment: A bifactor exploratory structural equation modeling representation. Structural Equation Modeling, 25, 267-286.

Tóth-Király, I., Morin, A.J.S, Gillet, N., Bőthe, B., Nadon, L., Rigó, A., \& Orosz, G. (2020).

Refining the assessment of need supportive and need thwarting interpersonal behaviors using the bifactor exploratory structural equation modeling framework. Advance online publication. doi: $10.1007 / \mathrm{s} 12144-020-00828-8$

Trépanier, S.G., Fernet, C., \& Austin, S. (2016). Longitudinal relationships between workplace bullying, basic psychological needs, and employee functioning: A simultaneous investigation of psychological need satisfaction and frustration. European Journal of Work and Organizational Psychology, 25, 690-706.

Trépanier, S.-G., Forest, J., Fernet, C., \& Austin, S. (2015). On the psychological and motivational processes linking job characteristics to employee functioning: Insights from self-determination theory. Work \& Stress, 29, 286-305.

Van den Broeck, A., Ferris, D.L., Chang, C.H., \& Rosen, C.C. (2016). A review of selfdetermination theory's basic psychological needs at work. Journal of Management, 42, 1195.

Van den Broeck, A., Vansteenkiste, M., De Witte, H., Soenens, B., \& Lens, W. (2010). Capturing autonomy, competence, and relatedness at work: Construction and initial validation of the WorkRelated Basic Need Satisfaction scale. Journal of Occupational and Organizational Psychology, $83,981-1002$.

Van der Elst, T., Van den Broeck, A., De Witte, H., \& De Cuyper, N. (2012). The mediating role of frustration of psychological needs in the relationship between job insecurity and work-related well-being. Work \& Stress, 26, 252-271.

van Hooff, M.L., \& van Hooft, E.A. (2017). Boredom at work: Towards a dynamic spillover model of need satisfaction, work motivation, and work-related boredom. European Journal of Work and Organizational Psychology, 26, 133-148. 
Vandenberg, R.J., \& Lance, C.E. (2000). A review and synthesis of the measurement invariance literature: Suggestions, practices, and recommendations for organizational research. Organizational Research Methods, 3, 4-69.

Vansteenkiste, M., Lens, W., Soenens, B., \& Luyckx, K. (2006). Autonomy and relatedness among Chinese sojourners and applicants: Conflictual or independent predictors of well-being and adjustment? Motivation and Emotion, 30, 273-282.

Vansteenkiste, M., Ryan, R.M. \& Soenens, B. (2020). Basic psychological need theory: Advancements, critical themes, and future directions. Motivation and Emotion, 44, 1-31.

Wang, C., Hsu, H.C.K., Bonem, E.M., Moss, J.D., Yu, S., Nelson, D.B., \& Levesque-Bristol, C. (2019). Need satisfaction and need dissatisfaction: A comparative study of online and face-to-face learning contexts. Computers in Human Behavior, 95, 114-125.

Wanous, J.P., Reichers, A.E., \& Hudy, M.J. (1997). Overall job satisfaction: How good are singleitem measures? Journal of Applied Psychology, 82, 247-252.

Weigelt, O., Syrek, C.J., Schmitt, A., \& Urbach, T. (2019). Finding peace of mind when there still is so much left undone-A diary study on how job stress, competence need satisfaction, and proactive work behavior contribute to work-related rumination during the weekend. Journal of Occupational Health Psychology, 24, 373-386.

Yu, S., Levesque-Bristol, C., \& Maeda, Y. (2018). General need for autonomy and subjective wellbeing: A meta-analysis of studies in the US and East Asia. Journal of Happiness Studies, 19, 1863-1882. 
STATES

\begin{tabular}{|c|c|c|c|c|}
\hline & & Satisfaction & Unfulfillment & Frustration \\
\hline & Autonomy & $\begin{array}{l}\text { Autonomy } \\
\text { satisfaction }\end{array}$ & $\begin{array}{l}\text { Autonomy } \\
\text { unfulfillment }\end{array}$ & $\begin{array}{l}\text { Autonomy } \\
\text { frustration }\end{array}$ \\
\hline NEEDS & Competence & $\begin{array}{c}\text { Competence } \\
\text { satisfaction }\end{array}$ & $\begin{array}{l}\text { Competence } \\
\text { unfulfillment }\end{array}$ & $\begin{array}{c}\text { Competence } \\
\text { frustration }\end{array}$ \\
\hline & Relatedness & $\begin{array}{c}\text { Relatedness } \\
\text { satisfaction }\end{array}$ & $\begin{array}{l}\text { Relatedness } \\
\text { unfulfillment }\end{array}$ & $\begin{array}{c}\text { Relatedness } \\
\text { frustration }\end{array}$ \\
\hline
\end{tabular}

Figure 1. The $3 \times 3$ Psychological Need States Model. 
Table 1

Results from the Predictive Analyses for the ESEM solution (Study 2)

\begin{tabular}{|c|c|c|c|c|c|c|c|c|c|}
\hline \multirow[b]{2}{*}{ Outcomes } & \multicolumn{3}{|c|}{ Supportive behaviors } & \multicolumn{3}{|c|}{ Thwarting behaviors } & & & \\
\hline & $b$ & $S E$ & $\beta$ & $b$ & $S E$ & $\beta$ & & & \\
\hline Relatedness satisfaction & 1.107 & $.148 * *$ & .789 & -.243 & $.117^{*}$ & .151 & & & \\
\hline Autonomy satisfaction & .397 & $.119 * *$ & .000 & -.318 & $.133 *$ & -.280 & & & \\
\hline Competence satisfaction & .135 & .119 & .132 & .243 & .145 & .313 & & & \\
\hline Relatedness frustration & .008 & .114 & .258 & 1.022 & $.163 * *$ & .806 & & & \\
\hline Autonomy frustration & -.213 & .112 & -.097 & .651 & $.133 * *$ & .368 & & & \\
\hline Competence frustration & .008 & .101 & .323 & .418 & $.149 * *$ & .141 & & & \\
\hline Relatedness unfulfillment & -.277 & $.089 * *$ & .065 & .392 & $.098 * *$ & .109 & & & \\
\hline Autonomy unfulfillment & -.343 & $.104 * *$ & -.067 & .519 & $.123 * *$ & .226 & & & \\
\hline \multirow[t]{2}{*}{ Competence unfulfillment } & -.283 & $.118 *$ & -.017 & .204 & .123 & -.099 & & & \\
\hline & \multicolumn{3}{|c|}{ Autonomy satisfaction } & \multicolumn{3}{|c|}{ Competence satisfaction } & \multicolumn{3}{|c|}{ Relatedness satisfaction } \\
\hline Outcomes & $b$ & $S E$ & $\beta$ & $b$ & $S E$ & $\beta$ & $b$ & $S E$ & $\beta$ \\
\hline Boredom & .011 & .100 & .010 & .150 & .176 & .114 & -.179 & $.076^{*}$ & -.220 \\
\hline Rumination & .120 & .120 & .101 & -.301 & .193 & -.214 & .038 & .105 & .043 \\
\hline \multirow[t]{2}{*}{ Satisfaction } & -.030 & .044 & -.042 & -.053 & .046 & -.062 & .348 & $.039 * *$ & .659 \\
\hline & \multicolumn{3}{|c|}{ Autonomy frustration } & \multicolumn{3}{|c|}{ Competence frustration } & \multicolumn{3}{|c|}{ Relatedness frustration } \\
\hline Outcomes & $b$ & $S E$ & $\beta$ & $b$ & $S E$ & $\beta$ & $b$ & $S E$ & $\beta$ \\
\hline Boredom & -.044 & .122 & -.043 & .164 & .217 & .133 & -.161 & .190 & -.173 \\
\hline Rumination & .798 & $.131 * *$ & .723 & .064 & .216 & .048 & .019 & .195 & .019 \\
\hline \multirow[t]{2}{*}{ Satisfaction } & -.072 & .049 & -.108 & -.120 & $.053 *$ & -.149 & .118 & $.055^{*}$ & .195 \\
\hline & \multicolumn{3}{|c|}{ Autonomy unfulfillment } & \multicolumn{3}{|c|}{ Competence unfulfillment } & \multicolumn{3}{|c|}{ Relatedness unfulfillment } \\
\hline Outcomes & $b$ & $S E$ & $\beta$ & $b$ & $S E$ & $\beta$ & $b$ & $S E$ & $\beta$ \\
\hline Boredom & .141 & .164 & .136 & .306 & .188 & .253 & .302 & $.127 *$ & .267 \\
\hline Rumination & .060 & .127 & .054 & .044 & .170 & .034 & -.141 & .116 & -.116 \\
\hline Satisfaction & .071 & .048 & .105 & -.163 & $.056^{*}$ & -.208 & -.104 & $.039 *$ & -.141 \\
\hline
\end{tabular}

Note. ${ }^{*} p<.05 ; * *<<.01 ; b$ : unstandardized regression coefficient; SE: standard error of the coefficient; $\beta$ : standardized regression coefficient 


\section{Appendix}

\section{Final 37-item version of the PNSW-S}

Stem: In my job... [Dans mon activité professionnelle,...]

Autonomy Satisfaction [Satisfaction du besoin d'autonomie]

...I feel free to make choices with regards to the way I work [...je me sens libre de faire des choix quant à ma manière de travailler] (aS1)

...I have a say in how things are done [...j'ai mon mot à dire quant à la manière de faire les choses] (aS2)

...I have the freedom to make decisions about my work [...j'ai la liberté de prendre des décisions quant à mon travail] (aS3)

Competence Satisfaction [Satisfaction du besoin de compétence]

...I feel that I am capable [...je me sens compétent.e] $(\mathrm{cS} 1)$

...I feel skilled [...je me sens qualifié·e] (cS2)

...I am able to overcome challenges [...je me sens capable de surmonter des challenges] (cS3)

Relatedness Satisfaction [Satisfaction du besoin d'affiliation sociale]

...I feel supported [...je me sens soutenu·e] $(\mathrm{rS} 1)$

...I feel listened to [...je me sens écouté·e] (rS2)

...I feel valued $[\ldots$ je me sens estimé·e] $(\mathrm{rS} 3)$

...I feel cared for [...j'ai le sentiment d'avoir de l'importance aux yeux des autres] (rS4)

...I feel included [...je me sens intégré·e] (rS5)

...I feel valued as an important member of my group [...je me sens considéré·e comme un membre important de mon groupe] (rS6)

Autonomy Frustration [Frustration du besoin d'autonomie]

...I feel pushed to behave in certain ways [...j'ai le sentiment d'être poussé e à me comporter d'une certaine manière] (aF1)

...I feel forced to follow decisions about my work [...je me sens forcé·e de suivre des decisions] $(\mathrm{aF} 2)$

...I feel a lot of unwanted pressure [...je ressens une énorme pression dont je me passerais volontiers] (aF3)

...I feel forced to do professional tasks that I would not choose to do [...je me sens obligé.e de participer à des tâches que je n'aurais pas choisies] (aF4)

Competence Frustration [Frustration du besoin de compétence]

...I feel like a failure [...j'ai le sentiment d'être un·e raté·e] $(\mathrm{cF} 1)$ 
...I feel useless [...je me sens inutile] (cF2)

...I feel incapable [...je me sens incompétent·e] (cF3)

...I feel hopeless [...je me sens nul·le] (cF4)

Relatedness Frustration [Frustration du besoin d'affiliation sociale]

...I feel rejected [...je me sens rejeté·e] $(\mathrm{rF} 1)$

...I feel brushed aside [...j'ai le sentiment d'être mis·e à l'écart] $(\mathrm{rF} 2)$

...I feel disliked [...je me sens détesté·e] $(\mathrm{rF} 3)$

...I feel excluded [...je me sens exclu.e] $(\mathrm{rF} 4)$

...I feel isolated [...je me sens isolé.e] (rF5)

Autonomy Unfulfillment [Inassouvissement du besoin d'autonomie]

...I am unsure as to why we do certain professional tasks [...je ne sais pas trop pourquoi on fait certaines taches] (aU2)

...I am confused as to when I can make decisions [...je ne sais jamais vraiment quand je peux, ou non, prendre des decisions] (aU5)

...I often do not understand the rationale behind the tasks that I have to realize [...souvent, je ne comprends pas la justification des tâches que je dois réaliser] (aU6)

...I often do not understand the rationale for how my job is expected to be done [...souvent je ne comprends pas pourquoi mon travail doit être réalisé de cette façon] (aU7)

Competence Unfulfillment [Inassouvissement du besoin de compétence]

...I feel like I have achieved less than I would have liked to [...j'ai le sentiment de réaliser moins de choses que ce que je voudrais] (cU2)

...I feel like I have improved less than I would have liked to [...j'ai le sentiment de m'être moins amélioré·e que je ne l'aurais voulu] (cU3)

...generally, I am not satisfied with my performance [...je ne suis généralement pas satisfait.e de ma performance] (cU6)

Relatedness Unfulfillment [Inassouvissement du besoin d'affiliation sociale]

...I have little in common with others [...j'ai peu de choses en commun avec les autres] (rU1)

...I have little shared interest with others [...je partage peu d'intérêts avec les autres] (rU2)

...I feel I don't quite fit in with others [...je ne me sens pas à ma place avec les autres] (rU3)

...I have no close friends [...je n'ai pas d'ami-e.s proche.s] (rU4)

...I feel like others know little about me [...j'ai le sentiment que les autres me connaissent peu] (rU5) 